\title{
Evaluation of a knowledge transfer scheme to improve policy making and practices in health promotion and disease prevention setting in French regions: a realist study protocol
}

\author{
Linda Cambon ${ }^{1,27^{*}}$ D, Audrey Petit ${ }^{1}$, Valery Ridde ${ }^{3,4}$, Christian Dagenais ${ }^{5}$, Marion Porcherie ${ }^{1}$, Jeanine Pommier ${ }^{1}$, \\ Chrisine Ferron ${ }^{6}$, Laetitia Minary ${ }^{2}$ and François Alla ${ }^{2}$
}

\begin{abstract}
Background: Evidence-based decision-making and practice are pivotal in public health. However, barriers do persist and they relate to evidence properties, organisations and contexts. To address these major knowledge transfer (KT) issues, we need to rethink how knowledge is produced and used, to enhance our understanding of decision-making processes, logics and mechanisms and to examine the ability of public health services to integrate research findings into their decisions and operations. This article presents a realist evaluation protocol to assess a KT scheme in prevention policy and practice at local level in France.

Methods/design: This study is a comparative multiple case study, using a realist approach, to assess a KT scheme in regional health agencies (ARS) and regional non-profit organisations for health education and promotion (IREPS), by analysing the configurations contexts/mechanisms/outcomes of it. The KT scheme assessed is designed for the use of six reviews of systematic reviews concerning the following themes: nutrition, alcohol, tobacco smoking, physical activity, emotional and sexual life and psychosocial skills. It combines the following activities: supporting the access to and the adaptation of scientific and usable evidences; strengthening professionals' skills to analyse, adopt and use the evidences in the course of their practices and their decision-making process; facilitating the use of evidence in the organisations and processes. RAMESE II reporting standards for realist evaluations was used.

Discussion: The aims of this study are to experiment and characterise the factors related to the scheme's ability to enable public health stakeholders to address the challenges of KT and to integrate scientific knowledge into policy and practice. We will use the realist approach in order to document the parameters of successful KT strategies in the specific contexts of preventive health services in France, while seeking to determine the transferability of such strategies.
\end{abstract}

Keywords: Knowledge transfer, Realist evaluation, Complex intervention, Prevention, Public health

\footnotetext{
* Correspondence: Linda.cambon@ehesp.fr

1 UMR 6051 (CRAPE-Arenes), EHESP, Paris, France

EA 4360, APEMAC, Université de Lorraine, Nancy, France

Full list of author information is available at the end of the article
} 


\section{Background}

Evidence-based decision-making and practice are major issues in public health. For researchers, this means looking ahead to the dissemination of findings and integrating different types of knowledge and decision-making challenges [1]. It also implies greater collaboration between the research community and decision-makers [2]. Public health research issues have to be approached alongside societal and health issues too. It follows that evidence-based policy-making and planning in public health offer a way to improve the efficiency, credibility, and sustainability of health systems [1]. Furthermore, this can lead to a better social acceptance of the chosen decisions and interventions [3].

Despite the general agreement about the interest of evidence informed practices and policy-making (EIDM), barriers do persist in both the production and use of evidence. These barriers relate to people, organisations, contexts and properties of evidences [4]. To address this, it is necessary to rethink how knowledge is produced and used, to enhance our understanding of decisionmaking processes, logics and mechanisms and to examine the ability of public health services to integrate research findings into their decisions and operations. This requires a systemic approach, which includes the adaptation of scientific knowledge, the ability of users to capture, understand and apply the available evidence, as well as an accurate organisation and a supportive culture for using evidence. These are the major challenges of KT, defined by the National Public Health Institute of Quebec (INSPQ) as "the group of activities and interaction mechanisms that foster the dissemination, adoption and appropriation of the most up-to-date knowledge possible for use in professional practice and in healthcare management" [5].

\section{What stands in the way of the use of scientific evidence in public health?}

In France, there is no formal and structural KT scheme. There are a few initiatives led by the National Public Health Agency (ANSP) and the National Cancer Institute (INCA), which for instance produce literature reviews. But policy-makers and prevention professionals do not use them. It confirms that a passive diffusion of knowledge is not effective, and the effectiveness of $\mathrm{KT}$ strategies depends on the context in which they are implemented [6-10]. The contextualization of the KT strategies is necessary to remove barriers to knowledge use. According to Gervais et al. [3, 11], KT research on decision-making processes offers a number of explanatory factors which may be classified in three categories. The first relates to the specific properties of the evidence itself: nature, availability, accessibility, quality and credibility (data and sources), intelligibility, ability to meet needs, adaptability and transferability [3]. The second category relates to the personal characteristics of decision-makers: beliefs or personal values, political leanings, socio-demographics, level of education, previous experiences, motivation and ability to interpret data, etc. All of them may influence how new knowledge is addressed in the decision-making process.[12]. The third category refers to the characteristics of the organisations and local contexts in which knowledge producers and users work [4]: openness to change, material, human and financial resources available for $\mathrm{KT}$, social and political context in the external environment, style of management, leadership, staffing, stakeholder coalitions, etc. Consequently, the multiple barriers to the adoption of evidence in the field of public health underline the nonlinear process between knowledge production and knowledge use. If these barriers are to be overcome, we need to address all the parameters that affect the decisionmaking process. This is a focal point for KT research.

\section{The mechanisms of an effective knowledge transfer}

Various strategies are available to overcome barriers to the use of KT. A recent work conducted by Langer et al. identified six mechanisms involved in effective $\mathrm{KT}$ :

- "Awareness" (M1) is defined as building awareness for, and positive attitudes toward, evidence-informed decision-making (EIDM). This mechanism emphasises the importance of decision-makers' valuing the concept of EIDM.

- "Agree" (M2) is defined as the building mutual understanding and agreement on policy-relevant questions and the kind of evidence needed to answer them. This mechanism emphasises the importance of building mutual understanding and agreement on policy questions and what constitutes fit-for-purpose evidence.

- "Communication and access" is (M3) defined as providing communication of, and access to, evidence. This mechanism emphasises the importance of decision-makers receiving effective communication of evidence and convenient access to it.

- "Interact" (M4) is defined as the interaction between decision-makers and researchers. This mechanism emphasises the importance of decision-makers interacting with researchers in order to build trusted relationships based on mutual trust, collaborate, and gain exposure to a different type of social influence.

- "Skills" (M5) is defined as supporting decisionmakers to develop skills in finding and making sense of evidence. This mechanism emphasises the importance of decision-makers' having the necessary skills to identify, appraise, synthesise evidence, and integrate it with other information and political needs. 
- "Structure and process" (M6) is defined as influencing decision-making structures and processes. This mechanism emphasises the importance of decision-makers' psychological, social and environmental structures and processes (e.g. personal models, professional norms, habits, organisational and institutional rules) in providing means and barriers to action.

The authors underline that these strategies are effective if combined and contextualized in their implementation setting, confirming previous work of Ridde et al. [13] and Barwick [14]. Consequently, we hypothesize that in France, as elsewhere, simple diffusion and "one size fits all" strategies are not effective.

In this paper, we present the protocol of a realist evaluation study of knowledge transfer strategies implemented in the field of health prevention at a local level in France. We have used RAMESE II reporting standards for realist evaluations [15].

\section{Study objectives and location}

The objective of the study is to identify the configurations contexts/mechanisms/outcomes of an effective KT scheme in local prevention sector. This study will be conducted in four French regions and within two types of organisation and their partners: regional health agencies (ARS), which are responsible for policy-making and prevention policies; and non-profit organisations (IREPS). IREPS develop health promotion and prevention programs and provide methodological supports to field professionals for the implementation of prevention interventions in different settings (work places, schools, care settings, recreation and community centres, rural or urban areas, etc.). ARS and IREPS work together to implement prevention and health policies in local contexts.

\section{Methods/design}

We have reported this manuscript in line with the RAMESES II reporting standards for realist evaluation.

\section{Study design and conceptual framework}

This study is a comparative multiple case study of a KT scheme in the field of health prevention using a realist approach $[16,17]$. It concerns French public health services: ARS and IREPS. The case study design is the more suitable research strategy to investigate a phenomenon within its context and analyse this phenomenon's interactions with several other elements relevant for our area of study [18].

The realist approach [17] is increasingly used for appraising the interactions between an intervention, its mechanisms and its contexts. The overall aim is to achieve a better understanding of an intervention's success factors and how these may be replicated in other contexts. This type of evaluation examines what works, under what conditions and for whom, based on a middle-range theory (or configurational theory) which describes the interactions between outcomes, mechanisms and contexts $[17,19]$. Thus, realist evaluation integrates the paradigm of black box evaluation [20]. While the experimental paradigm evaluates effectiveness without appraising an intervention's mechanisms of impact, realist evaluation answers the following question: did the intervention work according to the theory underpinning it? This type of evaluation seeks to understand the intervention by focusing on its mechanisms and the influence of context. The mechanism is defined in this case as the "part of a participant's response to an intervention, generally hidden and sensitive to variations in context, and which produces effects" [21]. In realist evaluation, causality is generative, meaning that what generates the effect relates specifically to the interactions between context and cause (here, the intervention methods) [19]. However, as we will study the patterns between these interactions in different contexts, we hypothesise that it is possible to isolate key elements that may apply across a set of contexts. These findings will thus generate intermediate theories that will be sharpened little by little as each case will be investigated.

To conduct a realist evaluation, we alternate theoretical and empirical stages (Cf. Fig. 1: The realist sequences). According to Langer's work [2] and many authors $[7,10,13,14,22]$, we hypothesize that an effective KT scheme has to combine an access to and an adaption of knowledge, the development of professionals' skills to analyse, adopt and transfer knowledge into their contexts, the improvement of organisations and processes in order to facilitate the integration of knowledge. We also conducted an exploratory qualitative study in the four regions to collect data on the pre-existing scheme and activities related to $\mathrm{KT}$ and the potential local barriers. The questions were the following: what kind of KT activities are possible (types, timeline, duration, management)? Who may be involved? What structural/organisational mechanisms would be affected? What contextual factors, outside the control of those involved, would need to be addressed? Data will be collected by means of semistructured interviews with IREPS directors and ARS public health directors (8 people). Based on the behaviour change wheel theory [23] and an exploration of the behavioural theories used in KT strategies [24], we hypothesize that the change of which will occur in knowledge use may be notably due to the motivation to use knowledge, the perception of its usefulness and practicality and the ability to adapt it in to fit different settings. 


\section{INITIAL MIDDLE RANGE THEORY}

An effective KT scheme combines a relevant access to and an adaptation of knowledge, the development of professionals' skills to analyse, adopt and transfer knowledge into their contexts, the improvement of organisations and processes in order to facilitate the integration of knowledge. These strategies influence the motivation to use knowledge, the perception of its usefulness and practicality, the ability to adapt it to fit different settings, and produce evidence informed decision-making and practices .
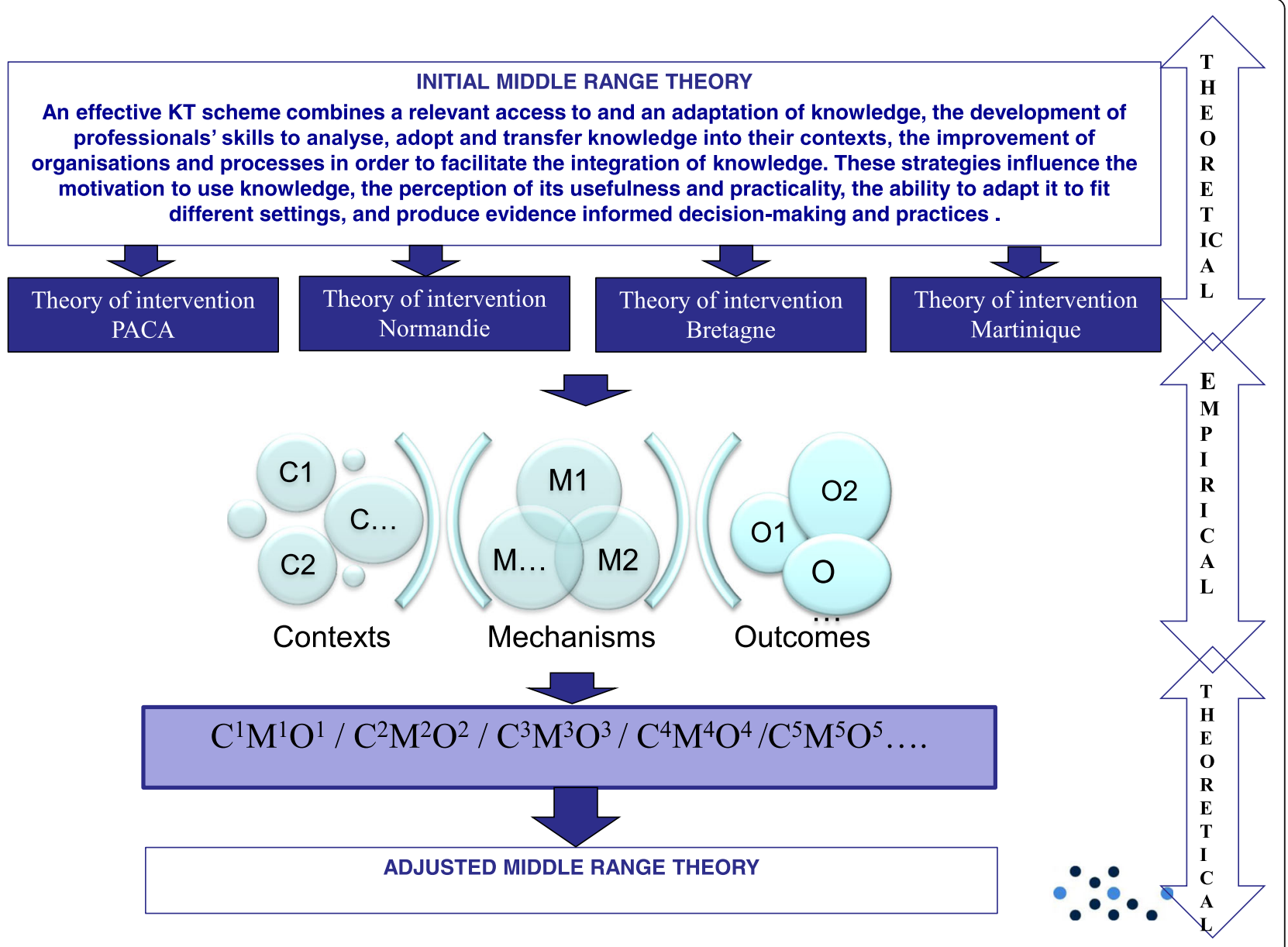

Fig. 1 The realist sequences describes the empirical/theoretical sequences of the realist evaluation

According to all the above scientific literature, and to support our realist evaluation, we built an initial middle range theory, defined as following: "An effective KT scheme combines a relevant access to and an adaptation of knowledge, the development of professionals' skills to analyse, adopt and transfer knowledge into their contexts, the improvement of organisations and processes in order to facilitate the integration of knowledge. These strategies influence the motivation to use knowledge, the perception of its usefulness and practicality, the ability to adapt it to fit different settings, and produce evidence informed decision-making and practices".

This initial middle range theory leads to the design of four theories of intervention one for each region describing the interventions, the expected outcomes, the contexts' parameters and the expected mechanisms. This work will be conducted in a preliminary 2-day workshop, gathering ARS and IREPS professionals. These theories will be applied in the 4 regions, for 12 months, and data will be collected in order to characterize the contexts, mechanisms and outcomes and to determine the effective CMO configurations.

Finally, a cross-sectional analysis of the case studies will be conducted allowing us to identify potential regular CMO patterns, which would constitute an adjusted middle-range theory. The different stages are presented in Fig. 1 (Cf Fig. 1: The realist sequences).

\section{Intervention strategies}

The intervention is a KT scheme designed for the use of policy briefs (PBs), which will be written on the basis of six reviews of systematic reviews (completed by international guidelines); an international scientific committee have carried out these reviews. They concern the following themes: nutrition, alcohol, tobacco smoking, physical activity, emotional and sexual life and psychosocial skills. These themes are primary in France. They present effective prevention practices.

Based on the report entitled "The science of using science: researching the use of research evidence in decisionmaking" [25], the scheme combines the following activities: 
- Supporting the access to and the adaptation of scientific and usable evidences especially the policy briefs.

- Strengthening professionals' skills to analyse, adopt and use the policy briefs in the course of their practices and their decision-making process (training, journal club, tutoring, etc.).

- Facilitating the use of evidence in the organisations and processes (collaborative workshops, normative processes, incentives, nudge, etc.).

According to the initial middle range theory and the 4 theories of change, professionals will make an action plan to apply them in their local settings. Theses KT activities will be set up over a 12-month period.

\section{Population}

The targeted population is composed of prevention and public health services operating in French regions, namely, the ARS and IREPS and their partners. The study will focus on three groups of stakeholders:

- ARS public health professionals: five agents per region (deputy directors in charge of prevention, heads of strategy departments and project managers);

- IREPS professionals: ten people per region (directors, project managers and communication managers).

- Members of specialised prevention commissions within the Regional Conferences on Health and Autonomy (CRSA) and members of the Public Policy Coordination Commission (CCPP) both devoted to prevention in French regions (five people) and partners of IREPS and ARS.

We already have the agreement for the data collection given by the four ARS involved in the project since it began.

\section{Data collection}

Data will be collected to document the support scheme's mechanisms and contexts parameters involved in effectiveness. They will be collected before the implementation of the KT scheme at the end and throughout the implementation. They will be collected on the 3 categories of people described before; 20 people per each region (80 at all).

Collected data will characterise the context, the mechanisms relating to the organisation and to the individuals involved, the PBs and the set-up for KT.

A description of data collected and how and they will be collected are presented in Tables 1 and 2, but these variables will be adjusted according to the four theories of intervention and the action plans (Cf. Table 1 : Expected outcomes and Table 2 : Contexts and mechanisms expected).

Data will be collected by means of:

- Semi-structured interviews conducted with the above-mentioned population (20 people per region)

- The observation of health promotion meetings and collective events resulting from the scheme's implementation: project selection committees, selection processes, trainings, seminars, presentations etc. The aim of these observations is to study the types of interactions between the professionals who deal with KT strategies (for instance, leadership, uptake, bottom up or top down approaches).

- A documentary analysis (calls for project, action plans, projects applications, reports of meeting, etc.)

The observation and documentary analysis grids and the interview guideline will be designed based on the four intervention theories and tested on a sample of five stakeholders not involved in the process, but belonging to the IREPS network.

The collection will last 12 months.

\section{Data analysis}

Data will be processed through a content analysis [26] defined as "A set of systematic and objective procedures for analysing communication processes in order to obtain indicators (quantitative or not) inferring knowledge related to the conditions (inferred variables) under which meaningful information is both sent and received". This analysis will code, classify and grade content in order to identify patterns, trends and specific features. We will use a software program called Nvivo to assist us in conducting and integrating a thematic analysis of the interviews and an analysis of the observation reports. The qualitative analysis will lead to:

- Document the uptake of evidence and the practice changes triggered by the intervention. This will be carried out on a case-per-case basis in monographic format, in order to identify the mechanisms at play, the degree of intervention, the contextual contingencies and the changes arising in the three types of knowledge use (instrumental, conceptual, persuasive).

- Identify the most regular CMO configurations by a cross-analysis of the different cases and a combination of the different data collected according to their linkage with the "context" meanings, "mechanism" meanings and "outcomes" meanings (cf Tables 1 and 2). 
Table 1 Expected outcomes

\begin{tabular}{|c|c|c|c|}
\hline Stakeholders & Outcomes & Indicators & $\begin{array}{l}\text { Data } \\
\text { collection }\end{array}$ \\
\hline \multirow[t]{4}{*}{ ARS } & $\begin{array}{l}\text { Agents use policy } \\
\text { briefs (PBs) in } \\
\text { discussions at } \\
\text { committee level }\end{array}$ & $\begin{array}{l}\text { Number of } \\
\text { verbatims per } \\
\text { meetings } \\
\text { Type of PBs or } \\
\text { extracts from PBs } \\
\text { Ways of using PBs }\end{array}$ & $\begin{array}{l}\text { Semi- } \\
\text { structured } \\
\text { interview } \\
\text { Observation }\end{array}$ \\
\hline & $\begin{array}{l}\text { Agents use } \\
\text { evidences from PBs } \\
\text { as criteria of project } \\
\text { assessment }\end{array}$ & $\begin{array}{l}\text { Existing in } \\
\text { assessment grids }\end{array}$ & $\begin{array}{l}\text { Documentary } \\
\text { analysis } \\
\text { Semi- } \\
\text { structured } \\
\text { interview }\end{array}$ \\
\hline & $\begin{array}{l}\text { Agents use } \\
\text { evidences from PBs } \\
\text { as part of } \\
\text { conventional tools } \\
\text { agreed between } \\
\text { the ARS and its } \\
\text { implementers (e.g. } \\
\text { integration into } \\
\text { specialised library } \\
\text { and reference } \\
\text { services) }\end{array}$ & $\begin{array}{l}\text { Existence of } \\
\text { mentioned PBs or } \\
\text { extracts from PBs in } \\
\text { documents } \\
\text { Ways of using PBs }\end{array}$ & $\begin{array}{l}\text { Documentary } \\
\text { analysis } \\
\text { Semi- } \\
\text { structured } \\
\text { interview }\end{array}$ \\
\hline & $\begin{array}{l}\text { Agents advocate } \\
\text { evidences from PBs } \\
\text { in their productions } \\
\text { (communications, } \\
\text { reports, action } \\
\text { plans, etc.) }\end{array}$ & $\begin{array}{l}\text { Number of } \\
\text { communications, } \\
\text { reports, action } \\
\text { plans mentioning } \\
\text { PBS or extracts } \\
\text { from PBs }\end{array}$ & $\begin{array}{l}\text { Semi- } \\
\text { structured } \\
\text { interview } \\
\text { Observation } \\
\text { Documentary } \\
\text { analysis }\end{array}$ \\
\hline \multirow[t]{6}{*}{ IREPS } & $\begin{array}{l}\text { Professionals use } \\
\text { evidences from PBs } \\
\text { to design their } \\
\text { projects }\end{array}$ & $\begin{array}{l}\text { Number of projects } \\
\text { mentioning PBs or } \\
\text { extracts from PBs } \\
\text { Ways of using PBs }\end{array}$ & $\begin{array}{l}\text { Semi- } \\
\text { structured } \\
\text { interview } \\
\text { Documentary } \\
\text { analysis }\end{array}$ \\
\hline & $\begin{array}{l}\text { Professionals use } \\
\text { evidences from PBs } \\
\text { to evaluate their } \\
\text { projects }\end{array}$ & $\begin{array}{l}\text { Number of } \\
\text { evaluation based } \\
\text { on PBs or extracts } \\
\text { from PBs } \\
\text { Ways of using PBs }\end{array}$ & $\begin{array}{l}\text { Semi- } \\
\text { structured } \\
\text { interview } \\
\text { Documentary } \\
\text { analysis }\end{array}$ \\
\hline & $\begin{array}{l}\text { Professionals use } \\
\text { evidences from PBs } \\
\text { to make reports to } \\
\text { their sponsors }\end{array}$ & $\begin{array}{l}\text { Number of } \\
\text { reporting based on } \\
\text { PBs or extracts } \\
\text { from PBs } \\
\text { Ways of using PBs }\end{array}$ & $\begin{array}{l}\text { Semi- } \\
\text { structured } \\
\text { interview } \\
\text { Documentary } \\
\text { analysis }\end{array}$ \\
\hline & $\begin{array}{l}\text { Professionals use } \\
\text { evidences from PBs } \\
\text { in the } \\
\text { methodological } \\
\text { supports for field } \\
\text { professionals }\end{array}$ & $\begin{array}{l}\text { Number of } \\
\text { methodological } \\
\text { supports based on } \\
\text { PBs or extracts } \\
\text { from PBs } \\
\text { Ways of using PBs }\end{array}$ & $\begin{array}{l}\text { Semi- } \\
\text { structured } \\
\text { interview } \\
\text { Observation }\end{array}$ \\
\hline & $\begin{array}{l}\text { Professionals } \\
\text { advocate evidences } \\
\text { from PBs in their } \\
\text { productions } \\
\text { (communications, } \\
\text { reports, action } \\
\text { plans, etc.) }\end{array}$ & $\begin{array}{l}\text { Number of } \\
\text { communications, } \\
\text { reports, action } \\
\text { plans mentioning } \\
\text { PBS or extracts } \\
\text { from PBs }\end{array}$ & $\begin{array}{l}\text { Semi- } \\
\text { structured } \\
\text { interview } \\
\text { Observation } \\
\text { Documentary } \\
\text { analysis }\end{array}$ \\
\hline & $\begin{array}{l}\text { Professionals use } \\
\text { evidences from PBs } \\
\text { as part of } \\
\text { conventional tools } \\
\text { agreed with their }\end{array}$ & $\begin{array}{l}\text { Existence of } \\
\text { mentioned PBs or } \\
\text { extracts from PBs in } \\
\text { documents } \\
\text { Ways of using PBs }\end{array}$ & $\begin{array}{l}\text { Documentary } \\
\text { analysis } \\
\text { Semi- } \\
\text { structured } \\
\text { interview }\end{array}$ \\
\hline
\end{tabular}

Table 1 Expected outcomes (Continued)

\begin{tabular}{|c|c|c|c|}
\hline \multirow{3}{*}{$\begin{array}{l}\text { Field } \\
\text { professionals }\end{array}$} & $\begin{array}{l}\text { sponsors, included } \\
\text { ARS and partners. }\end{array}$ & & \\
\hline & $\begin{array}{l}\text { Field professionals } \\
\text { use evidences from } \\
\text { PBs to design their } \\
\text { projects }\end{array}$ & $\begin{array}{l}\text { Number of projects } \\
\text { mentioning PBs or } \\
\text { extracts from PBs } \\
\text { Ways of using PBs }\end{array}$ & $\begin{array}{l}\text { Semi- } \\
\text { structured } \\
\text { interview } \\
\text { Documentary } \\
\text { analysis }\end{array}$ \\
\hline & $\begin{array}{l}\text { Field professionals } \\
\text { use evidences from } \\
\text { PBs to design their } \\
\text { conventional tools } \\
\text { with partners and } \\
\text { sponsors }\end{array}$ & $\begin{array}{l}\text { Existence of } \\
\text { mentioned PBs or } \\
\text { extracts from PBs in } \\
\text { documents } \\
\text { Ways of using PBs }\end{array}$ & $\begin{array}{l}\text { Documentary } \\
\text { analysis } \\
\text { Semi- } \\
\text { structured } \\
\text { interview }\end{array}$ \\
\hline CRSA & $\begin{array}{l}\text { CRSA committee } \\
\text { use evidences from } \\
\text { PBs to make } \\
\text { statements }\end{array}$ & $\begin{array}{l}\text { Number of } \\
\text { verbatim per } \\
\text { meetings } \\
\text { Type of PBs or } \\
\text { extracts from PBs } \\
\text { Ways of using PBs }\end{array}$ & $\begin{array}{l}\text { Observation } \\
\text { Documentary } \\
\text { analysis } \\
\text { Semi- } \\
\text { structured } \\
\text { interview }\end{array}$ \\
\hline ССРP & $\begin{array}{l}\text { CCPP committee } \\
\text { use evidences from } \\
\text { PBs to design their } \\
\text { partnership aim, } \\
\text { their common } \\
\text { projects }\end{array}$ & $\begin{array}{l}\text { Number of } \\
\text { verbatim per } \\
\text { meetings } \\
\text { Type of PBs or } \\
\text { extracts from PBs } \\
\text { Ways of using PBs }\end{array}$ & $\begin{array}{l}\text { Observation } \\
\text { Documentary } \\
\text { analysis } \\
\text { Semi- } \\
\text { structured } \\
\text { interview }\end{array}$ \\
\hline
\end{tabular}

Based on the observed elements, we will classify the outcomes in three categories of use as recorded in the literature $[27,28]$.

- Instrumental use: knowledge users draw on the IBs to make decisions or to change their practice;

- Conceptual use which implies changes in understanding and thinking inspired by the IBs;

- Persuasive use (also called strategic or symbolic use) which refers to a use of knowledge as a means to justify decisions or actions.

We will process these data to characterise the mechanisms identified in the intervention theory and induced by the intervention. This will enable us to answer the following questions about several mechanisms related to knowledge, people and organisations: (1) were they present in the contexts studied? (2) Did they positively or negatively influence the outcomes from a user's perspective? (3) Which mechanism(s) was (were) actually active (which parameter influenced which other parameter and/or which outcome)? (4)Which outcome(s) was (were) produced?

Then, a secondary middle range theory will then be developed, leading to future guidelines.

\section{Development of an adjusted middle range theory}

Based on this analysis, we will compare the CMO configurations, which will be identify with the initial middle range theory, and we will figure out an adjusted middle range theory. This work will be conducted during a 
Table 2 Contexts and mechanisms expected

\begin{tabular}{|c|c|c|c|}
\hline Types of variable & $\mathrm{CMO}$ & Types & Variables \\
\hline \multirow[t]{3}{*}{$\begin{array}{l}\text { Context in each } \\
\text { region }(C)\end{array}$} & & $\begin{array}{l}\text { Relating to regional policy- } \\
\text { making and policy action on } \\
\text { prevention }\end{array}$ & Leadership \\
\hline & & & $\begin{array}{l}\text { How public health is } \\
\text { organised }\end{array}$ \\
\hline & & & $\begin{array}{l}\text { Support mechanisms } \\
\text { for stakeholders/ } \\
\text { practitioners }\end{array}$ \\
\hline
\end{tabular}

\begin{tabular}{ll} 
Questions & $\begin{array}{l}\text { Data } \\
\text { collection }\end{array}$ \\
\hline Type of management & Observation \\
Type of management structuring & Documentary \\
& analysis \\
& Semi- \\
& structured \\
& interview
\end{tabular}

Funders

Observation

Types of funding ways (competitive call Documentary for project, conventional agreement, analysis etc.)

Assessment of actions

Main partnership between

Semi-

interview stakeholders.

Types of supporting process

Who support the practitioners

Who are supported

Who fund the supporting activities

Observation

Documentary

analysis

Semi-

structured

interview

Opportunities

Opportunities to work with researchers, to use evidences from researchers in practices

Observation

Documentary

analysis

Semi-

structured

interview

Collaborative

Experiences of collaborating work with researchers

Assessment of them

bservation

Documentary

analysis

Semi-

structured

interview

Specific decisionmaking and oper-

Description of decision-making process Description of designing, setting and ational process

Observation

Documentary

analysis

Semi-

structured

interview

Parameters Mechanisms Relating to the PBs

influencing the use (M)

of the PBs

Acceptability of PBs

Closeness between practices and PBs recommendations

Convenience of PBs with context and practices

Observation

Documentary

analysis

Credibility perceived of PBs

Other mechanisms not expected

Semi-

structured

interview

Relating to stakeholders/

professionals

Ability to integrate new practices in the context, in the habits (capabilities)

Interest from PBS using

Culture of change existing (previous experiences, awareness,

agreement)

Motivation of using PBs

Levels of interaction between researchers and practitioners to

discuss about evidence-informed practices

Other mechanisms not expected

Relating to organisations

Others
Changes in ability to evolve (opportunities in functioning, hierarchical agreement, etc.)

Temporality (opportunity to take time to introduce new knowledge coming from PBs)

Other blocking or driving mechanisms not expected

Other mechanisms not envisaged initially
Observation

Documentary

analysis

Semi-

structured

interview

Observation

Documentary

analysis

Semi-

structured

interview

Observation

Documentary analysis 
Table 2 Contexts and mechanisms expected (Continued)

\begin{tabular}{|c|c|c|c|}
\hline & & & $\begin{array}{l}\text { Semi- } \\
\text { structured } \\
\text { interview }\end{array}$ \\
\hline Conduct of the KT & Intervention (I) set up locally & $\begin{array}{l}\text { Type of KT activity set up locally } \\
\text { Duration of these activities (action plans) } \\
\text { Types of activity carried out } \\
\text { Stage of completion of the expected activities } \\
\text { Contributors involved in KT strategies } \\
\text { Partnerships involved in KT strategies } \\
\text { Financial resources in KT strategies } \\
\text { Material resources in KT strategies }\end{array}$ & $\begin{array}{l}\text { Observation } \\
\text { Documentary } \\
\text { analysis } \\
\text { Semi- } \\
\text { structured } \\
\text { interview }\end{array}$ \\
\hline
\end{tabular}

second interdisciplinary workshop, based on a discussion about analysis from data collected, gathering all ARS staff responsible for prevention and public health, IREPS directors and project officers, plus agents from ANSP and INCA.

KT development guidelines in France will emerge from this meeting.

\section{Communication and dissemination of results}

Different types of actors will be involved throughout the study: prevention professionals, policy-makers and researchers. Thus, multiple methods will be used to communicate research results:

- Developing short and practical policy briefs about knowledge transfer to national policy-makers and practitioners

- Delivering presentations at local, national meetings in France and relevant international meetings for professionals and researchers

- Regular project review meetings and continuous engagement with key decision-makers and practitioners, in particular as part of the Public Health Initiative for the Interaction between Research, Intervention and Decision-Initiative en Santé Publique pour l'Interaction entre la Recherche, l'Intervention et la Décision (InSPIRe-ID), a knowledge transfer consortium, led by the French Ministry of Health.

- Delivering presentations at national and international conferences and publishing articles in peer-reviewed academic journals with emphasis on open access

- Developing a project research report for the funder, with a publishable executive summary

\section{Discussion}

This article describes a protocol using a realist design to understand how a KT scheme works, for whom and in what circumstances. In research, realist evaluation is valuable for evaluating interventions in their contexts; it addresses contextual factors in relation to the mechanisms and outcomes of these interventions. Thus, partial patterns can be revealed to explain how interventions may foster enhanced KT.

However, even if there is weak support in France to develop $\mathrm{KT}$ at a local level, $\mathrm{KT}$ is highly recommended by health national authorities. Consequently, we need to address a potential social desirability bias, resulting both from the subject and the fact that the data are not selfreported [28]. This bias results from the tendency of survey respondents to answer questions in a manner that will be viewed favorably by others. Moreover, we will design the interventional scheme with the different stakeholders. Researchers are thus involved in the assessed process. This contextual parameter must be taken into account in the evaluation.

The aim of this study is to experiment and characterise the success factors of a KT scheme in health promotion and disease prevention settings. By success, we mean the scheme's ability to (1) enable public health stakeholders to address the challenges of $\mathrm{KT}$ and (2) bring about changes in public health policy and practice: integration of evidence-informed public health, collaborative practices etc. We will seek to explain the parameters and conditions of these strategies in order to determine their transferability into other contexts. This will provide a basis for the production of operational and contextualised guidelines in order to develop KT to inform regional policy-making on health promotion and disease prevention. Ultimately, this research aims at enhancing overall policy-making and quality of implementation in the sector. With this in mind, this project will be of great interest for public policy-makers who are currently moving towards evidence-informed health promotion and disease prevention in France.

\footnotetext{
Abbreviations

ANSP: Agence Nationale de Santé Publique (National Agency for Public Health); ARS: Agence Régionale de Santé (Regional Health Agency); CCPP: Commission de Coordination des Politiques Publiques (Public Policy Coordination Committee); CRSA: Conférence Régionale de la Santé et de I'Autonomie (Regional Conference on Health and Autonomy); FNES: Fédération Nationale d'Education et de promotion de la Santé (National Federation for Health Education and Promotion); I: Intervention; IB: Intervention brief; INCa: Institut National du Cancer (National Cancer
} 
Institute); InSPIRe-ID: Initiative en Santé Publique Pour I'Interaction entre la Recherche, I'Intervention et la Décision (a public health initiative dealing with the interaction between research, intervention and decision-making); INSPQ: Institut National de santé publique du Québec (Quebec Public Health Expertise and Reference (entre); IREPS: Instance Régionale d'Education et de Promotion de la Santé (a non-profit organisation promoting health at a regional level); KT: Knowledge translation; PACA: Provence-Alpes-Côte-d'Azur (region in the south of France)

\section{Acknowledgements}

The authors are very grateful to all those who took part in the project especially the members of the regional support teams and the Fédération Nationale d'Education pour la Santé

\section{Funding}

This research has received funding from a national recognized research agency; the IReSP. This funding has been obtained via a national competitive peer review grant application process, named "2016 General call for projects-Prevention" (No.,CAMBON-AAP16-PREV-11).

\section{Availability of data and materials}

Not applicable

\section{Authors' contributions}

$L C$ and AP drafted this article and all authors revised the manuscript. The project design was developed by LC and AP. LM, FA, JP, MP and CF were involved in implementing the project and in developing the evaluation design. VR and CD were involved in the design of the middle range theory. All authors read and approved the final manuscript.

\section{Competing interests}

The authors declare that they have no competing interests.

\section{Consent for publication}

Not applicable

\section{Ethics approval and consent to participate}

The project will be carried out with full respect of current relevant legislation (e.g. the Charter of Fundamental Rights of the EU) and international conventions (e.g. Helsinki Declaration). The methods development, data collection and analysis will take account of the following issues:

- Anonymity of study respondents will be preserved and ensured at all times as respondent(s) request. Unnecessary collection of personal data will be avoided, and respondents will have the right to review outputs and withdraw consent. All personal data will be coded, removed from the data for analysis and stored separately. Only designated research staff will have access to the keys linking the data with the personal information.

- Informed consent will be obtained from all study participants, and in the case of refusal, alternative means of data collection will be explored (e.g. alternative respondents).

In addition, this study has received approval from the national agency for data protection Commission Nationale Informatique et Libertés (NS no. 43, registered under number $2028640 \vee 0$ ).

\section{Publisher's Note}

Springer Nature remains neutral with regard to jurisdictional claims in published maps and institutional affiliations.

\section{Author details}

'UMR 6051 (CRAPE-Arenes), EHESP, Paris, France. '2EA 4360, APEMAC, Université de Lorraine, Nancy, France. ${ }^{3}$ Department of Social and Preventive Medicine, University of Montreal School of Public Health (ESPUM), Montreal, Canada. ${ }^{4}$ University of Montreal Public Health Research Institute (IRSPUM), Montreal, Canada. ${ }^{5}$ Department of Psychology, University of Montreal, Montreal, Canada. ${ }^{6}$ Fédération Nationale d'Education et de promotion de la Santé (FNES), Paris, France. ${ }^{7}$ EHESP, Paris, France.
Received: 11 May 2017 Accepted: 15 June 2017

Published online: 29 June 2017

\section{References}

1. Alla F, Cambon L. Recherche interventionnelle en santé publique, transfert de connaissances et collaboration entre acteurs, décideurs et chercheurs. Quest Santé Publique. 2014:12:1-4.

2. Langer L, Tripney J, Gough D. The science of using science: researching the use of research evidence in decision-making. London: EPPI-Centre, Social Science Research Unit, UCL Institute of Education, University College London; 2016.

3. Gervais MJ, Chagnon F. Modélisation des déterminants et des retombées de I'application des connaissances issues de la recherche psychosociale. Québec: Fonds québécois de recherche sur la société et la culture; 2010. p. 85.

4. Gervais M, Gagnon F, Bergeron P. Les conditions de mise à profit des connaissances par les acteurs de santé publique lors de la formulation des politiques publiques: L'apport de la littérature sur le transfert des connaissances. Montréal : Chaire d'Etude CJM-IU-UQAM; 2013.

5. Castiglione S, Ritchie J. Passer à l'action: nous connaissons les pratiques que nous souhaitons changer. Que faire, maintenant? Guide de mise en oeuvre pour les professionnels de la santé [Internet]. Instituts de Recherche en Santé du Canada; 2012 [cited 2017 Feb 28]. Available from: http://www.cihrirsc.gc.ca/f/45669.html

6. Landry R, Amara N, Lamari M. Utilization of social science research knowledge in Canada. Res Policy. 2001;30:333-49.

7. Dagenais C, Ridde V, Laurendeau M-C, Souffez K. Knowledge translation research in population health: establishing a collaborative research agenda. Health Res Policy Syst. 2009;7:28.

8. Grol R. Successes and failures in the implementation of evidence-based guidelines for clinical practice. Med Care. 2001;39:||46-54.

9. Grol R, Grimshaw J. From best evidence to best practice: effective implementation of change in patients' care. Lancet. 2003;362:1225-30.

10. LaRocca R, Yost J, Dobbins M, Ciliska D, Butt M. The effectiveness of knowledge translation strategies used in public health: a systematic review. BMC Public Health. 2012:12:751.

11. Gervais MJ, Gagnon F, Bergeron P. Les conditions de mise à profit des connaissances par les acteurs de santé publique lors de la formulation des politiques publiques : I'apport de la littérature sur le transfert des connaissances. Montréal: Chaire d'étude CJM- IU-UQAM sur l'application des connaissances dans le domaine des jeunes et des familles en difficulté; 2013.

12. Jabot F. L'évaluation des politiques publiques: cadres conceptuel et étude de son utilisation par les décideurs des institutions régionales de santé en France [Internet]. Université de Lorraine; 2014 [cited 2017 Feb 14]. Available from: http://www.theses.fr/2014LORR0201

13. Ridde $V$, Dagenais $C$, Boileau-Falardeau M. Une synthèse exploratoire du courtage en connaissance en santé publique. Santé Publique. 2013;25(2):137-45.

14. Barwick MA, Peters J, Boydell K. Getting to uptake: Do communities of practice support the implementation of evidence-based practice? J Can Acad Child Adolesc Psychiatry. 2009;18:16-29.

15. Wong G, Westhorp G, Manzano A, Greenhalgh J, Jagosh J, Greenhalgh T. RAMESES II reporting standards for realist evaluations. BMC Med. 2016;14(1):96.

16. Pawson R. Evidence-based policy: a realist perspective. 2006.

17. Pawson R, Tilley N. Realistic Evaluation. London: Sage Publications Ltd; 1997.

18. Yin RK. Case Study Research: Design and Methods. 5th ed. Los Angeles: SAGE Publications, Inc; 2013. p. 312

19. Blaise $P$, Marchal $B$, Lefèvre $P$, Kegels $G$. Au-delà des méthodes expérimentales: I'approche réaliste en évaluation. In: Potvin L, Moquet M-J, Jones C, editors. Réduire les inégalités sociales de santé. Saint-Denis: INPES; 2010. p. 285-96.

20. Salter KL, Kothari A. Using realist evaluation to open the black box of knowledge translation: a state-of-the-art review. Implement Sci IS. 2014;9:115.

21. Ridde $\mathrm{V}$, Robert $\mathrm{E}$, Guichard $\mathrm{A}$, Blaise $\mathrm{P}$, van Olmen J. L'approche réaliste à l'épreuve du réel de l'évaluation des programmes. Can J Program Eval. 2012;26(3):37-59.

22. Tchameni Ngamo S, Souffez K, Lord C, Dagenais C. Do knowledge translation (KT) plans help to structure KT practices? Health Res Policy Syst. 2016:14:46.

23. Michie S, Van Stralen MM, West R. The behaviour change wheel: A new method for characterising and designing behaviour change interventions. Implement Sci. 2011;6:42. 
24. Wehn U, Montalvo C. Knowledge transfer dynamics and innovation: behaviour, interactions and aggregated outcomes. J Clean Prod. 2016. [cited 2017 May 10]; Available from: http://linkinghub.elsevier.com/retrieve/pii/ S0959652616315396.

25. Langer L, Tripney J, Gough D. The science of using science: researching the use of research evidence in decision-making. London: EPPI-Centre, Social Science Research Unit, UCL Institute of Education: University College London; 2016

26. Bardin L. L'analyse de contenu. 2nd ed. Paris: PUF; 2013.

27. Straus SE, Tetroe J, Graham ID, Zwarenstein M, Bhattacharyya O, Shepperd S. Monitoring use of knowledge and evaluating outcomes. CMAJ Can Med Assoc J. 2010;182(2):E94-8.

28. Nass C, Moon Y, Carney P. Are respondents polite to computers? Social desirability and direct responses to computers. J Appl Soc Psychol. 1999; 29(5):1093-110

Submit your next manuscript to BioMed Central and we will help you at every step:

- We accept pre-submission inquiries

- Our selector tool helps you to find the most relevant journal

- We provide round the clock customer support

- Convenient online submission

- Thorough peer review

- Inclusion in PubMed and all major indexing services

- Maximum visibility for your research

Submit your manuscript at www.biomedcentral.com/submit 